\title{
Disclosure and performance: expecting more, and better
}

T hose of us who start each day with that double assault on the nerves, a cup of coffee and the morning paper, are growing accustomed to bad-news stories in health care. A recent example is the revelation by reporter Barry Meier in the New York Times ${ }^{1}$ that 3 years before warnings were issued by federal regulators an implantable cardioverter defibrillator was known to have the potential to malfunction. ${ }^{1}$ The reason offered by company officials for their failure to inform patients about an electrical flaw in a small proportion of units was that publicizing the problem might do more harm than good, given the low rate of device failure and the risks of replacement surgery. ${ }^{2}$ Consequently, the option of weighing these risks for himself was never offered to 21-year-old Joshua Oukrop, who died on a cycling trip when his implanted defibrillator failed.

Although the failure of a company (and the FDA and Health Canada) to disclose information on device performance in a timely manner is deplorable and worthy of media headlines (and, one hopes, corrective action) at least performance was being monitored. When it comes to the provision of routine medical care in the hospital or office, performance is almost completely unmonitored. And what is not monitored cannot be disclosed.

Hospitals, with seriously ill patients requiring complex medical care, are particularly dangerous places. The overall incidence rate of adverse events that result in death, disability or prolonged hospital stay in Canadian hospitals is 7.5 per 100 hospital admissions, of which $37 \%$ are preventable (95\% confidence interval $32 . \%-42 \%$ ): this amounts to an estimated 70000 serious preventable adverse events a year. ${ }^{3}$

If these figures are discomfiting to the public (and to physicians), we would do well to consider the insidious manner in which medical error and adverse events can arise. The Canadian Adverse Events Study pointed in large measure to failures in diagnosis, the prescription of contraindicated drugs and the incorrect management of organ failure.

But there are other, perhaps more common, failures that are not being monitored. These are failures to manage patients according to widely accepted standards of care. Although such failures may not result in an adverse event during a hospital stay, they place patients at increased and unnecessary risk. For example, we know that patients with acute myocardial infarction ought to receive prescriptions for $\beta$-blockers and ASA, barring specific contraindications. Some patients receive care that mirrors guideline recommendations, and others don't. This application of evidence- based standards is irregular. This is the type of amorphous quality-of-care issue that does not get much attention in the media. Nor do patients necessarily know whether or not they are receiving substandard care.

Granted, there is no precise formula for much of medical practice, which relies on each physician's ability to tailor treatment decisions to an individual patient's needs. But, for many conditions, widely accepted standards are broadly applicable across almost all patient groups. Such process-of-care standards could be implemented in hospital and ambulatory practice; adherence could be monitored and the results disclosed. Patients and the public are able to understand the nuances, to understand risk adjustments for disease severity and to use this information appropriately. More important, disclosing process and outcome results will push physicians and other health care providers to improve their scores by delivering care that more clearly reflects widely accepted standards.

In the United States, attempts are being made to monitor practice for patients with specified conditions and to accredit physicians on successfully attaining established standards in actual practice. These results are disclosed (see www.ncqa.org/PhysicianQualityReports.htm). For hospitals, monitoring is even easier than in ambulatory care: electronically accessible records of care and outcomes already exist in patient discharge summaries. By using such records, it is possible to compare performance of hospitals for several important conditions such as the management of acute myocardial infarction, pneumonia, congestive heart failure and pregnancy. In the United States, standards have been developed, performance is monitored and results are disclosed (see www.jcaho.org and www.cms.hhs.gov /quality/hospital). Public disclosure has led to improvements in underperforming hospitals. ${ }^{4}$

In Canada, such data, if they exist, are not publicly disclosed. Let's not be distracted by the headlines. There is much to attend to in the day-to-day practice of medicine. - CMAJ

\section{References}

1. Meier B. Maker of heart device kept flaw from doctors. New York Times 2005 May 24;Sect A:1.

2. Steinbrook R. The controversy over Guidant's implantable defibrillators. $N$ Engl 7 Med 2005;353(3):221-4.

3. Baker GR, Norton PG, Flintoft V, Blais R, Brown A, Cox J, et al. The Canadian Adverse Events Study: the incidence of adverse events among hospital patients in Canada. CMA7 2004;170(11):1678-86.

4. Jha AK, Li Z, Orav EJ, Epstein AM. Care in US hospitals - the hospital quality alliance program. NEngl 7 Med 2005;353(3):265-74. 